\section{ON TRANSFUSION OF BLOOD.}

By IIENRY M. MADGE, M.D., Vice-Presicent of the Obstetrical Society of London.

THE object of this paper is to give a short résumé of the present state of the question of transfusion. 'The history of the subject is curious and varied. 'Transfusion has had, as it were, many ups and downs; now, for a time, attracting much attention and exciting great expectations, and then, for a long period, almost sinking into oblivion. To those who would like to diveinto itsinteresting historical details, I would recommend the writings of Martin of Berlin, Oré of Paris, Gesellius of St. Petersburg, and, among our own countrymen, Waller, Routh, and Aveling ; also the Transactions of the Royal Society, extending as far back as two centuries ago. Even at that remote period, transfusion was a good deal talked about, and the most exaggerated notions were formed of its capabilities. The old were to be made young, and enjoy perpetual youth, and all diseases, including insanity, were to be removed. As the operation came far short of such pretensions, and as one or two deaths followed its performance, it fell into disrepute and disuse. It is due to Dr. Aveling to say that the recent revival of the subject with us has been, in a great measure, brought about by a successful case of immediate transfusion, an account of which he read before the Obstetrical Society of London. The Society at once appointed a committee to collect evidence, and to test, as far as possible, the real claims of transfusion to the confidence of the profession. As honorary secretary to that committee, I am able to state that a great deal of evidence has been collected. Besides a good deal of oral evidence given before the committee by several eminent physicians, and the reception of several papers from British authors, numerous books, pamphlets, and instruments have been received from many parts of the continent. It is with the view of still further increasing this stock of information, that the committee have desired me to bring the subject before this meeting. We hope there may be some here who have had cases of transfusion, and will give us the results of their experience.

In theory, nothing can be more plausible than transfusion. A person is dying from loss of blood ; how easy it would appear to be to rescue that person from death by throwing blood back into the system. Again, a patient is gradually sinking from some morbid condition of the bloodpyæmia, chemical poisoning, or any form of blood-poisoning or bloodalteration. It seems feasible enough that to take away the morbid blood, and to replace it with blood taken from a healthy individual, would be sufficient to restore the patient to health. Unfortunately, however, in this matter, as in many others, practice does not run so smoothly as theory. With regard to blood-poisoning, an idea respecting hydrophobia has occurred to me, which I dare say has occurred to others. As all kinds of treatment hitherto devised for that formidable disease have proved useless, I would suggest that transfusion be tried, either by unloading the vessels of the poisoned blood, and injecting healthy blood, or by injecting some chemical solution into the veins, with the view of neutralising the poison. Leisrink, in a paper on transfusion (Volkmann's Sammlung Klinischer Vorträge, 1872), says :"Transfusion is indicated in all those pathological conditions where the blood, in quantity and quality, is so altered that it is unfit to fulfil its physiological duties." It is to obstetricians, however, that transfusion possesses the deepest interest. Although, of course, available in traumatic or any form of bleeding endangering life, it will, if it ever becomes a frequently performed operation, be more in connection with uterine hæmorrhage than with anything else. The immediate effects of injecting blood into the veins seem to have been very varied. Some have started up, as if from a long sleep, moved their limbs, and asked for food; others-even those who eventually recovered-have only slowly shown signs of returning life. In general, the pulse soon becomes stronger, the respirations more regular, and the skin warmer. Some have experienced rigors, and others a feeling of warmth throughout the system. If the favourable symptoms are not maintained, the operation should be repeated, because their appearance shows that the system is capable of responding to the means employed.

The forms of transfusion which are now most in vogue, and which have been attended with the greatest amount of apparent success, areI. Transfusion with defibrinated blood.

2. Mediate transfusion with pure blood.

3. Immediate transfusion from "vein to vein."

4. Immediate transfusion from " artery to vein."

I. Transfusion with Defibrinated Blood. - In most of the cases recently performed at home and abroad, defibrinated blood has been used. Dr. Playfair of London and Dr. Robert McDonnell of Dublin strongly recommend this plan. Dr. MEDonnell has had several successful cases, and one particularly interesting and successful in connection with the late Dr. Beatty (Dublin Quarterly Fournal, May 1870). The great advantage of using blood deprived of fibrin is, that there is no fear of clotting. This makes the operation easier than with pure blood, as it can be done more leisurely and without much assistance. The advocates of this plan say that fibrin, as it exists in venous blood, is waste material, and useless, and that the real revivifying element is the oxygen contained in the red corpuscles. This may, or may not, be true ; the balance of scientific opinion is in its favour; but, perhaps, there would be more candour shown in saying that the real reason for getting rid of the fibrin is, because it interferes with the operation. The opponents of the plan maintain that fibrin is an essential element of the blood, that it favours coagulation, helps to build up the tissues, and that, when its removal is attempted, there will always remain small particles or shreds, which may produce pyæmia or embolism. It is certainly true that, in many cases of recovery from impending death after transfusion with defibrinated blood, patients have died in a few weeks from pyiemia ; but, of course, this may have arisen from various other causes. If the defibrinating process be carefully done, there is not much danger of finding shreds of fibrin in the strained fluid. I have proved this by repeated microscopical examinations. The blood should be caught in a basin, and whipped with a fork, a small stick, or-as Dr. De Belina advises, for the sake of cleanliness (this is most important in dealing with transfusion) - one or two twisted glass-rods. After a few minutes, the fibrin will be found adhering to the rods, and the blood, having been strained two or three times through fine linen, is ready for use. Muslin or coarse linen must not be used for straining. Violent whipping must also be avoided, as it is supposed to be possible in this way to burst or damage the blood-corpuscles. There is no doubt that, with ordinary care, defibrinated blood may be safely in. jected into the veins. Numerous instances are on record where patients have survived its employment, and lived for years. ${ }^{*}$ This form of transfusion does not necessarily require a special apparatus; a common syringe has often been used with success. Indeed, most of the instruments that have been invented are merely modifications of an ordinary syringe.

Dr. De Belina has related a case in which transfusion was successfully employed in resuscitating a new-born child. The blood found with the placenta was defibrinated and injected into the umbilical vein with a common syringe (De la Transfusion du Sang Défibriné, Paris, 1873, p. 8). In devising instruments for using defibrinated blood, the great aim seems to have been to prevent air from entering the veins. Some are glass syringes fitted with a canule to enter the vein, and graduated to hold four or six ounces of blood-the quantity usually employed. When used, the piston is withdrawn, and the blood poured into the syringe from above; the piston is then replaced, and the contents of the syringe discharged, with one slow downward stroke, into the vein. The action of the piston, and consequent entrance of air, of the ordinary syringe is thus avoided. Dr. Braxton Hicks's instrument and Dr. Graily Hewitt's are made on this principle. Dr. McDonnell uses a glass cylinder in the form of a syringe, but without a piston, holding about six ounces; to the nozzle is fixed a long India-rubber tube, with a canule at one end to enter the vein. The blood in the cylinder finds its way into the vein partly by gravitation and partly by a small propelling bulb placed in the middle of the tube. If this be insufficient to drive the blood on, the operator blows gently, with the mouth applied to the opening at the top of the instrument. Dr. De Belina's instru. ment is somewhat similar ; but, instead of using the mouth to supply air-pressure, he uses an elastic tube and bulb, worked like an etherspray apparatus. There is no elastic tube fixed to the nozzle, which is curved and fitted with a canule. Dr. Richardson's instrument is much of the same character. Dr. Playfair uses a modification of Aveling's instrument. The end provided with the canule is placed in the opened vein, and the other in the vessel containing the prepared blood, and it

* Dr. Soutouguine, physician to the Cesarewitch, called on me when in London, and gave me an account of some experiments he had made on dogs. They were and gave me an account of some experiments he had made on dogs. They were undertaken to determine the immediate and remote effects of transfusion with defibrinated blood, and had evidently been performed with precision and care. One dog was first weighed, and, calculating in this way the amount of blood in its body, it was bled nearly to death, so that the beats of the heart were scarcely perceptible. Another dog was then served in the same way, and the defbrinated blood of one exper from erysipelas springing from the wound in the vessel, the remaining five quite recovered, and were observed to be in vigorous health for several months. For some time after the operation, they were weighed every day and their excretions examined, and found to be normal. Dr. Soutouguine also injected the blood of a rabbit into the veins of a dog, with the effect of causing bloody urine, wasting, and death. Experiments were also made with defibrinated blood that had been preserved for some time-the notion being that it might be kept always ready for use. The dogs that were transfused with it did very well. Although possible in Russia, this would hardly be a safe proceeding here. I have found that defibrinated blood has a special tendency to become rapidly stale and fotid. 
is then worked in a simple and effective way, like a Higginson's syringe. Many other instruments have been invented, but those I have mentioned are, perhaps, the most important, and all are well adapted for the purpose.

2. Mediate Transfusion with Pure Blood.-Using pure or non-defibrinated blood would, no doubt, be preferable in all cases, if it could be done with ease and safety; for, after all, defibrinated blood is a disorganised fluid, and is only used because the presence of fibrin is inconvenient. With pure blood, clots are apt to form and block up the instruments, and, what is of more consequence, small clots may enter the vein, and lead, like carelessly prepared defibrinated blood, to pyæmia and embolism. Notwithstanding its drawbacks, the use of pure blood has many advocates both at home and on the continent. Mr. Higgin. son of Liverpool has had the largest and most successful experience of mediate transfusion in this country. He has had fifteen cases, and ten were successful (Liverpool Medical and Surgical Reports, vol. v). $\mathrm{He}$ does not seem to have encountered much difficulty from clotting. The instrument which he has invented for the operation is, to some extent, a modification of the syringe which is known by his name. It is bulky in appearance, caused by the rather unnecessary precautions taken to keep the blood and the instrument warm, and to prevent the entrance of air into the vein. Modern views on this subject are very different from what they were. Up to very recently, it was always held to be of great importance that a certain high temperature of the blood should be maintained to prevent coagulation. Dr. Richardson and others have shown that heat favours coagulation, and that cold retards it. There is still a diversity of statements as to the exact time at which fresh-drawn blood begins to coagulate, owing, no doubt, partly to varying conditions of temperature, and the shape of the vessel used to receive the blood. The time is variously given from one minute to five or six minutes. Artificial cold is said to retard coagulation for several hours. A short time ago, in damp weather, the thermometer standing at $60 \mathrm{Fahr}$., I noticed that bullock's blood, received into a common basin, commenced to coagulate in about five minutes. This would give ample time for injecting the requisite amount of blood into the vein. The great point is to have everything ready, and not to take the blood from the arm of the donor until the arm of the patient is prepared and ready to receive it. The hurry to get through this form of the operation, for fear of clotting, is certainly one of its drawbacks. To prevent coagulation of the blood, Dr. Braxton Hicks has recommended the ad. dition of a small quantity of phosphate of soda (Guy's Hospital Reports, I868, p. I4), and Dr. Richardson minute quantities of ammonia. Even in very small proportions, the ammonia not only prevents or retards coagulation, but, in transfusion, it acts as a stimulant to the system. Great care is required in using it. Injected into the veins of a dog, insufficiently diluted, it produced convulsions ( $O_{n}$ the Coagulation of the Blood, 1856, p. I20). The entrance of air into the veins has always been one of the bugbears of transfusion. There is now reason to think that too much has been made of it. Oré has shown, by experiments on dogs, that a large quantity of air throw into the femoral vein will cause death in a few minutes, but that a small quantity, such as might accidentally get into the veins in ordinary transfusion cases, does no harm (Etudes sur la Transfusion du Sang, Paris, 1868). These experiments have been repeated by several German physiologists. With these considerations, one need not be afraid, in a case of emergency, of using an ordinary syringe, although, of course, the less air admitted the better. Many of the instruments used for defibrinated blood are almost equally well adapted for pure blood. The quantity used in Mr. Higginson's cases was from four ounces to twelve ounces-in one case, twenty ounces.

3. Immediate Transfusion from Vin to Vein. - The revival and improvement of this method in England is, we all know, due to Dr. Aveling, who has written so much and so hopefully about it, that we must all desire to see his hopes realised. An objection already noticed has been raised to venous blood. It is said to contain all the impure debris of the tissues, and must, therefore, be injurious. This perhaps would be met by saying that the veins are the proper receptacles for venous blood; and that, once in the patient's system, it soon becomes arterial. Theimmediate method has many supporters on the Continent, and instruments have been devised for its performance by MM. Mathieu, Longet, Dré, and others. The current of blood in the veins being without impetus, the difficulty of sending the blood from vein to vein through a small tube has been met in various ways, but by none so successfully as by Dr. Aveling. His simple and ingenious instrument consists of a small India-rubber tube about a foot long, with a bulb in the centre. The ends are provided with cannules for entering the veins respectively of the donor and the receiver of the blood; and, as Dr. Aveling says, it forms a sort of anastomosis between the two individuals. The blood is propelled along the tube by a manipulation of the bulb and of the tube itself, a knowledge of which can only be acquired by practice. I should recommend those who procure the instrument to practise passing water through it transfusion fashion-that is, according to Dr. Aveling's instructions (Obstetrical Transactions, 1865, p. I32). It only requires a little practice; but that little is essential, and will make its use much easier when it is really wanted. By the use of this instrument, the dangers of clotting and of the entrance of air are reduced to a minimum. Dr. Aveling's experience has not as yet been large, but the plan seems to carry with it the promise of great future success. Dr. Savage of Birmingham has recently used Aveling's instrument in a successful case of transfusion, and speaks very highly of it. Dr. Aveling does not think it necessary to follow the old plan of dissecting out the vein in the patient's arm and passing ligatures or a probe beneath it. $\mathrm{He}$ merely exposes the vessel, and makes an opening in it for the reception of the cannule, which is kept in its place by the finger and thumb of an assistant. Of course this proceeding is applicable to every form of transfusion. Dr. Schliep, of the German Hospital, uses a modification of Aveling's instrument. Instead of the ball in the centre of the tube, he substitutes a syringe, with double action, like that of a stomach-pump or aspirator. This seems to give a greater command over the blood passing through the tube, but the continued action of the syringe would probably lead to clotting. When it is difficult to get any one willing to be anastomosed with the patient, or if, during the operation, the donor of the blood should become faint, recourse must be had to the mediate method.

Immediate Transfusion from Artery to Vein.-This is the oldest form of transfusion; and, as the earlier operations were made on animals, no difficulty was experienced. The carotid artery of one animal was connected by means of a small tube, having small glass or metallic tubules at each extremity, with the jugular vein of another, the blood being driven onwards by the arterial impulse. When, however, arterial transfusion came to be applied to the human subject, opening an artery was considered to be too formidable an undertaking, and recourse was then had to the arterial blood of one of the lower animals-a sheep, lamb, calf, or dog. A great outcry was made against this. It was absurdly supposed that the transfused blood would carry with it something of the nature of the animal from which it was taken, and that patients would bleat like sheep and bark like dogs. The blood-corpuscles in many animals are larger than in man, and, it is supposed, would not easily pass through the human capillaries; but those of the lamb and the dog are smaller, and are, therefore, suitable for transfusion. At the present time, whenever arterial transfusion is attempted, the blood of the lamb is used.* A very interesting case of this kind has lately been published by Dr. Albini, Professor of Experimental Physiology in the University of Naples. The patient had severe menorrhagia, and was sinking from loss of blood and from inability to retain anything on the stomach. Transfusion was performed by connecting the carotid artery of a lamb, by means of an elastic tube, with one of the brachial veins. The good effects were perceptible at once, and the patient improved in a few days so as to be able to eat and drink almost as usual. On the eighth day, a fresh accession of hæmorrhage occurred. Transfusion was again performed on the following day, but this time without benefit. Severe rigors were experienced, and peritonitis from supposed extension of uterine disease set in ; and death soon followed. (Relazione sulla Trasfusione diretta di Sangue d'Agnello, Naples, 1873, p. 8). Another case of the same kind has recently occurred in America, the details of which I have not yet obtained. The bluod of the lamb should only be used when there is difficulty in obtaining human blood. There is something repulsive in the idea of bringing an animal into the sick-chamber, and of mixing animal with human blood. In this suggestion, however, there may be more of sentiment than of science. $t$ Shock to the patient would be avoided by obtaining the blood in an adjoining room, and using it pure or defibrinated, by the mediate method. For the immediate method, the lamb must be firmly secured by straps, the least movement being fatal to the operation. Professor Albini gives a drawing in his pamphlet showing how this is managed. Dr. Guerin of Paris is bold enough to recommend human arterial transfusion. It must, however, be left to surgeons to decide whether, under such circumstances, we should be justified in opening an important artery. There is this to be said for arterial transfusion, that the blood is purer; and the drawbacks to venous blood, defibrinated or otherwise, whatever they may * The London Medical Record (Dec. 3Ist) contains an account of twelve cases of the
direct transfusion of lamb's blood by Dr. Oscar Hasse. The patients were suffering direct transfusion of lam, dysentery, etc., and all were benefited. The account is from phthisis, chlorosis, dysentery, etc., and all were benented. December, by Mr. Bellamy.

+ As Dr. Barnes said in the discussion on the paper, "It is only taking lamb in another form." 
be, would be avoided. Dr. Guérin has repeated an experiment which was performed by Blundell and others long ago-a sort of double transfusion. Two dogs are placed side by side, and the carotid artery of each animal connected by means of a tube with the jugular vein of the other. In this way, they obtain a common circulation, after the fashion of the Siamese twins. Although a most interesting experiment, this can only be regarded as one of the curiosities of transfusion.

It might happen that it would be impossible to get a supply of blood of any kind just when it was wanted. In such a case, it would be an advantage to have a substitute at hand. Some have recommended milk others a very weak soluticn of ammonia. Saline solutions of various kinds have been used, also serum, or an imitation of it, particularly in cases of cholera; only, however, with partial success. The solu. tion should be about the same specific gravity as that of the blood; and, according to Dr. Pavy, the salts of potash should never be used (Guy's Hospital Reforts, 1868, page 6). Injecting plain water into the veins is dangerous, as it causes the blood-corpuscles to burst, and disorganises the blood. Further experiments are required to establish the safety and utility of saline solutions and other substitutes for blood in transfusion.

If the question be now asked, Which is the best and safest form of transfusion? I think it must be admitted that, in the present state of our knowledge, each of the four principal forms I have mentioned may be employed with an almost equal chance of success. $*$

For a more minute description of the various steps of the operation in the different modes of transfusion than I have given, and for fuller details of cases and descriptions of instruments, I must refer you to the writings of the authors whose names I have mentioned. It is one of the misfortunes of transfusion that, like a great many other therapeutic measures, its modus operandi is not quite understood. To place it on a sound scientific basis, we must know more than we do at present about the physiology and pathology of the blood. It will not do, however, to reject transfusion because we cannot explain the exact way in which it does good and saves life. If this rule were followed, we should have to give up nearly all our best remedies. It has generally been supposed that, when blood is injected into a vein of an almost moribund patient, for the purpose of resuscitation, it goes direct to the heart, which is stimulated to increased action by the presence of its natural stimulus. Hüter, however, states, and seems to have proved by experiment, that by venous transfusion the blood does not go direct to the heart, but becomes lost or diffused in the general venous system. $\mathrm{He}$ recommends arterial transfusion, but of a different kind to that already referred to - namely, sending blood to the heart through one of the arteries in the neighbourhood of that organ (Archiv fir Klin. Chir., vol. xii ; Contralblatt, 1869, No. 25). There are many obvious objections to this plan, and the trials and experiments that have been made to illustrate it are not encouraging. I mention it here partly for the boldness and novelty of the suggestion, and partly to show that we are still somewhat in the dark about this part of the subject. If Hiiter's theory regarding venous transfusion be correct, we get rid of one of the supposed dangers of transfusion-that is, over-distension of the right side of the heart. The dread of this danger has been pretty generally felt, and to avoid it we are cautioned to inject the blood slowly and in moderate quantities. It has been a matter of surprise with many, that the quantity of blood used in transfusion is so small, compared with the quantity lost; but, when a patient is reduced by loss of blood to the lowest ebb, a few ounces would be sufficient to turn the scale either way-by further abstraction, towards death; by addition, towards a restoration of the equilibrium of the circulation. Whether the latter is brought about by the mechanical effect of adding something to the bulk of the blood in the body, or by stimulating the heart and vessels, are points that can only be settled by experiment.

There are several other points connected with the subject surrounded with difficulties. Indeed, transfusion, although somewhat ancient, may still be said to be in its infancy. By many, it is altogether regarded with scepticism. It is said that those who recover after transfusion would recover just the same without it. One writer says that "transfusion is a sort of Will-o'-the-wisp of science, holding out the most brilliant prospects, which never seem to be realised." There is, no doubt, much in the history of transfusion to justify scepticism as to its real value ; but there is also no doubt that it has had its triumphs as well as failures. A large number of well authenticated cases of success are on record-quite enough to encourage us to thoroughly investigate the subject, to endeavour to remove all doubt, and thus, if possible, to secure to the profession an effective means of saving life when all other

* I ought, perhaps, to state that in this paper I am only giving my own opinions. No formal or definite conclusions have as yet been arrived at by the Committee. means fail ; for it must always be remembered that transfusion is only to be used as a last resource. In this important work, the Committee on Transfusion invite the co-operation of all those members of the British Medical Association who take an interest in the subject. The points calling for further inquiry appear to the Committee to be as follows.

I. The exact time that human blood takes to coagulate when drawn from a vein. (This is suggested from the different results arrived at by various authors, and from the fact that Mr. Higginson has found but little difficulty in transfusing blood in its natural state.)

2. Does blood, when injected into a vein, go direct to the heart, or does it become lost or diffused in the general venous system?

3. The effects, immediate and remote, of transfusion with blood kept in a state of non-coagulation by means of phosphate of soda, as recommended by Dr. Hicks.

4. The effects, immediate and remote, of transfusion with blood con taining ammonia, as recommended by Dr. Richardson.

5. The effects of transfusion with milk.

6. The effects, immediate and remote, of tranfusion with defibrinated blood.

7. The microscopic examination of defibrinated blood.

8. The effects of transfusion on one of the lower animals by the im. mediate method, on Dr. Aveling's plan, from an animal of the same species.

9. Transfusion with blood in its natural condition, as in Mr. Higgin son's cases.

10. Further inquiries to show whether the blood of the lamb or of any other animal might be introduced with impunity into the humar. system.

I I. Transfusion with defibrinated blood, with the addition of ammonia or phosphate of soda, or both combined.

12. Transfusion with saline solutions.

I3. Further experiments to show how long an animal deprived of food would live on blood transfused daily.

\section{REMOVAL OF A LOOSE CARTILAGE FROM A KNEE-JOINT UNDER THE ANTISEPTIC TREATMENT.}

By GEORGE LICHTENBERG, M.D., Surgeon to the German Hospital and Tottenham Training Hospital.

THE removal of loose cartilages in joints byoperation has been, and is even now, considered by most surgeons as a procedure connected with more or less risk ; and one which, according to their opinion, should only be resorted to when a palliative treatment previously tried has utterly failed. And if we examine minutely the statistics of this operation, we must confess that there is truth in this assertion; and no surgeon is to be blamed if he undertake the operation with a certain feeling of diffidence as to the ultimate result. Cases, however, will occur which imperatively demand the removal of loose cartilage by operation, which operation, great as the risk may be, is not comparable to the suffering and even danger in which the patient is placed by allowing it to remain; and here arises the question, What kind of operation should be performed? Is the loose cartilage to be removed by the direct incision or by the subcutaneous one? We all know that, according to present experience by the direct method, the risk to life is greater than by the subcutaneous one; while the latter operation is more difficult to perform, and therefore has resulted in more failures. But, speaking of the failure of the subcutaneous method, it would be neglect on my part not to mention the very favourable results which Mr. Square, Surgeon to the South Devon and East Cornwall Hospital in Plymouth, has achieved by his subcutaneous incision. Mr. Square refers to no fewer than twenty-four cases operated upon either by himself or by others according to his particular subcutaneous method; not one failure among them has taken place, and all cases, without exception, have made a rapid recovery. Having carefully read the different cases, I certainly should not hesitate to follow Mr. Square's advice, and not attempt to employ any other method than the subcutaneous incision for the removal of loose cartilages in joints, had not Professor Lister produced such a thorough revolution in the treatment of wounds by his antiseptic treatment. Although it lies not in the compass of these short remarks to enlarge upon this really grand achievement ( $\mathrm{I}$ am not entering into the details), I may be allowed here to mention that several years' experience has thoroughly convinced me that by this treatment conservative surgery has gained a triumph which, though at present I regret to say it is not fully appreciated, will in the future bear bountiful fruit, and 